\title{
Studies on Fungi Associated With Post Harvest Spoilage of Pawpaw Carica PAPAYA Fruit
}

\author{
${ }^{1}$ Awoite TM, ${ }^{2}$ Olorunfemi MF, ${ }^{3}$ Ajani AO and ${ }^{4}$ Oyelakin MO \\ ${ }_{1,2,3,4}$ Nigerian Stored Products Research Institute PMB 5044 Onireke Ibadan, Nigeria.
}

\begin{abstract}
A study was carried out to find out fungi associated with the spoilage of pawpaw fruits during their post harvest period. A total of fifteeen strains of fungi were isolated and identified as Aspergillus niger,Aspergillus flavus,Penicillium italicum, Rhizophus stolonifer and Neurospora sitophila.Pathogenicity test of each fungal isolate showed that all fungi were capable of causing rottening of the fruit and most severe rottening was caused by Rhizopus stolonifer while Aspergillus flavus produced the least rottening of the fruit.It was found that there was increase in acidity of the fruits as spoilage progressed while water content increased from $61.5 \%$ to $85.5 \%$ which account for the increase in the softness of the fruit during spoilage while the increase in acidity gave the fruits an acidic taste which is often bitter.
\end{abstract}

Key words: Carica papaya, fungi, pathogenicity, post harvest, spoilage.

\section{Introduction}

Pawpaw (Carica papaya) belongs to the family Caricacae constituting of four genera and thirty one species. The genera and species numbers are: Carica:22, Farilla:6, and Cyclicomorpha;(2).The papaya is native to Tropical South America, possibly in the area between Mexico and Central America (Menzel,1994). It is a widely grown pantropical fruit used for local consumption and assume some importance in trade in Hawaii which is a major producer of fresh fruits while Sri lanka and Tanzania are major producers of pawpaw for the enzyme papain (Umoh,1998).

The edible portion of papaya is composed mostly of water (86.8\%) and carbohydrate principally sugars with little starch(12.18\%) which together make up $98.98 \%$ of the fruit (Wenkam and Miller,1995).The acid content of papaya is very low, this would account for its lack of tartness and its relative high $\mathrm{pH}$ value of 5.9.The fruit contain a major enzyme called papain which is proteolytic. Pawpaw has been utilized widely in brewering and pharmaceutical industries(William et.al.,1980).

Spoilage in pawpaw can also be referred to as rot or decay. Spoilt pawpaw fruits is characterized by excess softening, mycelia growth, loss of moisture unpleasant odour, shrinkage and total drying up of water in the fruits(Franzier and Westhoff,1999).The spoilage may be caused by microorganisms, insects and rodents attack, physical injury such as bruising and freezing as well as chemical breakdown of the fruit may also lead to deterioration in quality of the fruit. The occurence of spoilage in fruits by microorganisms depends on the types of organisms present and whether the fruit under its existing condition of storage can support the growth of any or all of them. Only certain species out of all the organisms present in a fruit will be able to thrive well and spoil it. Spoilage by microorganisms may be influenced by some qualities such as water content, $\mathrm{pH}$ value, temperature, texture and nutrient composition of the fruit (Lloyd,1993).

Charley (1999) observed that fresh fruits carry out the physiological function of respiration, thereby absorbing and releasing gases and other materials from and to environment. This condition make them susceptible to microbial infection under condition of high ambient temperature and relative humidity which lead to their deterioration during post harvest period. Physiological stability of fruit varies, thus the main damage to the quality of the fruit does not occur generally until the microorganisms have gained access to the living tissues through the skin. Fruits come in contact with the disease causing organisms through different sources such as field infections or during harvesting if it comes in contact with the soil which is an important factor that aids spoilage of stored fruits.

Air is another factor responsible spoilage of fruits during their post harvest period, fungal spores are always in the air, these spores and other particulate ones constitutes the air spora (Holtmeyer and Wallin,1981). Also, transporting equipment after harvesting such as sack ,basins ,baskets e.t.c. can serve as major sources of transmission of the pathogens. Water used in washing the fruits may be contaminated with large numbers of microbes and as such transfer them directly to the fruit and due to the high nutritional constituents of the fruits they serve as a fertile ground for microbes especially fungi (Salunkhe,1974).

The aim of this study is to isolate and identify the fungi associated with the deterioration of pawpaw fruits after harvest and to determine the pathogenicity effect of the different isolates on healthy pawpaw fruits to ascertain that the fungi isolated were very much responsible for the spoilage and produce the disease symptoms. 


\section{Methodology}

Fruits collection: infected ripe pawpaw fruits were collected from different fruit stores at a popular fruit market in Ibadan, Nigeria. The fruits were collected into a sterile polythene bag and brought to the laboratory for the study.

Plating: Potato Dextrose Agar (PDA) used in this study were prepared according to the manufacturer's specification. Bacterial contamination was inhibited by aseptically adding $2 \mathrm{mls}$ of streptomycin to $1000 \mathrm{mls}$ of the sterile medium prior to pouring into sterile petri dishes. Surface sterilization of the infected portion of the fruits was done using $70 \%$ alcohol, the fruits were then rinsed with sterile distilled water. Small portion of the diseased parts of the fruits were carefully cut with sterile scapel and then transferred aseptically onto solidified PDA. The plates were then incubated at $26 \pm 1{ }^{\circ} \mathrm{C}$ temperature for 72 to 96 hours.

Isolation: The numbers and types of colonies on the plates were observed and noted at the end of incubation.Representative colonies were randomly picked and subcultured until pure culture of isolates were obtained.The pure cultures were maintained on agar slants which were kept as stock cultures under refrigeration temperature $\left(4^{0} \mathrm{C}\right)$ for subsequent use.

Characterization and Identification of Isolates: The isolates were characterised based on their colonial and cellular morphology.The colonial mophorlogy of the isolates were observed macroscopically and characteristics such as colour of mycelia and spores, shape and surface texture were noted. The isolates were then observed microscopically under light microscope for their cellular morphology using wet mounting method: On a drop of distilled water on a glass slide a small mycelial portion was introduced with an inoculating needle and then teased with the needle.Two drops of methylene blue was added,covered with a cover slip and observed under $\mathrm{x} 40$ objective lens for hyphal nature and disposition of mature fruiting structures. Appropriate drawings were made and the different characteristics of the fungal isolates were recorded. However,the various fungal isolates were compared with those of fungi in a compendium of pathogenic fungus by Barnnet and Hunter (1972).

Pathogenicity Test: Healthy mature pawpaw fruits were washed and surface sterilized with $70 \%$ alcohol. A sterile cork borer of $4 \mathrm{~mm}$ diameter was used in punching out single fruit column from each of the healthy pawpaw fruits.4mm disc of fungal mycelia punched from pure culture of each of the isolates using sterile cork borer, each disc was then removed using sterile inoculating loop and placed in the punched out space, one disc of fungal mycelia for one pawpaw fruit each. The inoculated points were covered with the fruit skin columns and then sealed up with Vaseline gel to prevent contamination by other organisms. All the inoculated fruits were put in microhumidity chamber.(Amadioha,1998). The pathogens were reisolated from the inoculated fruit samples, this was done by cutting out small portion of spoilt fruit sample with sterile scapel and inoculated directly onto sterile PDA plates which were incubated thereafter. The resultant growth were subcultured to obtain pure culture of the isolates and the isolates were reexamined macroscopically and microscopically.

$\mathrm{pH}$ Change During Spoilage :Four healthy pawpaw fruits were used.20g was weighed out of one of the ripe fruits and crushed in a beaker ,the crushed mass was transferred into a conical flask containing $20 \mathrm{mls}$ of distilled water, the mixture was properly shaken and allowed to settle. The $\mathrm{pH}$ of the supernatant was taken using $\mathrm{pH}$ meter and was recorded as $\mathrm{pH}$ for the first day and for healthy fruit used as control. The three other fruit samples were incubated to spoilage for 3days,6days and 9days separately and the $\mathrm{pH}$ of the different samples were taken on each day as described for the healthy pawpaw fruit.

Water Content Change During Spoilage: Twenty grams of spoilt pawpaw fruit was oven dried at $80^{\circ} \mathrm{C}$ for 30 minutes. The heated sample was cooled and the weight was taken. Drying and weighing were repeated for healthy fruit samples and results compared. The water content was determined and expressed as the percentage water content using the formula;

$$
\begin{aligned}
& \% \text { Moisture Content }=\left(\mathrm{W}_{1}-\mathrm{W}_{2}\right) \\
& \mathrm{W}_{1}
\end{aligned}
$$

\section{Results And Discussion}

The macroscopic observation of the diseased fruits showed brownish necrotic patches on the fruit's skin, the patches were a bit sunken and turned black with time. Cotton-like mycelia mass was also observed on the fruit's skin about 3 days from the beginning of the spoilage. The major symptoms of spoilage observed in the fruits was the soft rot and an unpleasant odour emanating from the spoilt fruits. The softness of the fruit increases with the number of days and the fruit could be punctured by any slight pressure apply on it. As the spoilage progressed the fruit's skin became damp due to loss of moisture and complete spoilage was characterized by the shrinkage of the whole fruit. 
The fungi isolated during the studies were identified as ;Aspergillus niger, Aspergillus flavus, Rhizopus stolonifer, Penicillum italicum and Neurospora sitophila.

Isolate F1:The colonies formed by this fungus appeared initially flat and dirty white but turned black at maturity due to production of black conidia. Microscopic examination showed the hyphae to be septate and branched.Conidiophores were club shaped with globose head,aseptate branched and erect.The conidiophores arose from a foot cell and terminated in a vesicle which give rise to chains of two or more spores suspended on the sterigma.The conidial head radiate and were compact, tending to split into loose columns with age.The spores were dark and oval in shape,the fungus was identified as Aspergillus niger.

Isolate F2: The colonies were dusty white and fluffy in appearance,they grew rapidly covering the whole surface of the culture plate within 48hours of incubation. Mycelia were interwoven and rhizoids were hair like structures.The fungus possessed well developed hyphae which branched freely and were coenocytic.Sporangiophores were brown coloured, smooth walled, aseptate, erect and opposite, the rhizoids developed from the hyphae.The sporangia were blackish brown at maturity and globose containing numerous spores which were angular or oval in shape and appeared singly.Well developed columnella were also revealed.The fungus was identified as Rhizopus stolonifer.

Isolate F3: Appeared At first as rough granular white colonies at first but turned yellowish green with maturity due to production of conidia. Microscopic examination revealed branched and septate hyphae.The conidiophores arose from thickened foot cells and were highly branched, aseptate' coenocytic erect and bore sterigmata on the globular vesicle on which the conidia were borne.The conidia were greenish, globose to subglobose in shape with rough surface and occur in chains of two or more.The fungus was identified as Aspergillus flavus.

Isolate F4: the colonies appeared pale green with pheripheral white colour, becoming bluish grey with maturation .Microscopic observation showed conidiophores as branched and septate, slightly long, smooth and swollen. The conidiophores also gives rise phialides which were thick walled and borne elliptical conidia which were globose with greenish smooth wall. The fungus was identified as Penicillium italicum.

Isolate F5: Initially the colonies were colourless, growing rapidly with irregular tufts especially at the margin of the PDA plates but became pinkish to orange with maturation. Conidiogenous hyphae were more or less ascending, walled septate with lateral branches which form chains of conidia connected by a narrow hyaline strand. The conidia are single celled usually ellipsoidal or less cylindrical to globose. The fungus was identified as Neurospora sitophila.

Pathogenicity Test of fungal isolate: In this test all the fungal isolates were observed positive for causing spoilage or rottening of pawpaw fruits.The various disease symptoms caused by each of the isolates were observed and recorded as follows; Aspergillus niger:This fungus a characteristics profuse mycelia growth.The lesion produced caused distention of the fruit surface. Fruit appeared water soaked and soft rot developed rapidly through the fruit tissues resulting in total rot, the fruit collapsed due to exudation of liqiuds.

Aspergillus flavus: This fungus cuased soft rot spoilage, necrotic patches were found on the fruit and they spread, the infected area became water soaked. Penicillium italicum:This fungus produced powdery mycelia on the fruit surface which did not extend much beyond the conidial mass.The decayed portion of the fruit was definite, soft and water soaked. The fruit gradually became a shapeless slimy mass. Rhizopus stolonifer: Rotteness produced by this fungus was the most severe, it produced mass of mycelia on the fruit surface which extends into the fruit and the fruit skin became damped. The fruit gradually reduced in mass as the spoilage progressed and finally collapsed due to loss of moisture.

Monilia sitophila: This fungus produced a massive growth of orange mycelia on the fruit surface, the fruit became softened and an unpleasant odour emanates from the fruit. The fruit skin became damp as a result of loss of moisture as the diseased progressed and finally became shrunk.

Effect of spoilage on $\mathrm{pH}$ value pawpaw: There was an increase in the acidity of the fruit with spoilage as shown in Table 1.

\begin{tabular}{ccc} 
& \multicolumn{2}{c}{ Table 1. Changes in pH of pawpaw fruits. } \\
Incubation Period(days) & Description of Fruit Samples & $\mathrm{pH}$ \\
1 & Riped healthy fruit & 6.9 \\
3 & Over riped pawpaw fruit & 6.5 \\
6 & Moderately spoilt fruit & 5.2 \\
9 & Absolutely spoilt fruit & 4.2
\end{tabular}

Changes in Water Content :The water content of the pawpaw fruit increases with days of spoilage. The water content of the pawpaw fruit increases from $61.5 \%$ to $85.5 \%$ within 7 days of spoilage. 


\section{Conclusion}

The result of pathogenicity test carried out showed that all the fungi isolated and identified in the study were pathogenic to the pawpaw fruit causing soft rot or decaying of the fruits. Aspergillus flavus and Aspergillus niger are wide spread in nature being found on fruits, vegetable and other substrates that provide nutrients since they can tolerate high concentration of sugar and salt. The Aspergilli have been found to be common pathogens of many crops and cause serious economic losses (Bayewu and Amusa,1999). Similarly,the isolated Rhizopus stolonifer cause food spoilage,grow on bread,vegetables,fruits and other food products.The fungus cause soft rot disease on pawpaw fruit,this has been reported by Patil (1973) and it is of considerable important post harvest decay organism. Penicilium italicum occur widely in nature and caused soft rot of the pawpaw fruit known as "blue mold of Citrus causing great spoilage (Dudkwort,1996). Neurospora sitophila has been found to cause spoilage in carbohyrate rich food products such as bread corn or maize by growing on their surface. However, the reaction of healthy pawpaw fruits to the inoculated fungal isolates showed that Rhizopus stolonifer cuased the most severe and aggressive rotting of the fruit followed by Penicillium italicum and then Neurospora sitophila while the two Aspergilli produced slight rotting of the fruits.The pathogenicity of Rhizopus stolonifer to cause the most aggresive rotting can be attributed to its ability to grow rapidly and due to the high water activity of the spoilt fruit which favours growth of the fungi generally. From this study the water content of a healthy fruit was $61.5 \%$ and increased to $88.5 \%$ with spoilage, this increase in water content account for the increase in the softness of the fruit during spoilage.

The acidity of the fruit increased with days due to spoilage. Consequently, the taste of spoilt fruit ranges from loss of good characteristic tastes to the development of objectionable tastes. Thus a spoilt fruit develops acidic taste which is often bitter (Ihekeronye and Ngoddy,1985).

The degree of post harvest spoilage of papaya fruit can be reduced so as to enhance longer shelf life and greater income. There are various post harvest treatments to control decay in papaya fruit, these include hot water treatment (Char,1983), high temperature forced air treatment(Robinson, et al,1993) and breeding of resistant variety of papaya. However, the only satisfactory measure against papaya spoilage is through hygiene, quarantine treatment procedures and vector control.

\section{Acknowledgement}

The authors appreciate the efforts of the research team of Nigerian Stored Products Research Institute for making this work a success and also the management team for allowing us to use their laboratory facilities.

\section{References}

[1] Barnnet HL, Hunter BB (1972). Illustrated genera of imperfect Fungi- APS press,Minnesota.

[2] Bayewu RA, Amusa NA (1999). Biochemical changes in pawpaw fruit infected with fungi In: Bioscience Research Communication 11: $257-261$.

[3] Chan HT (1983). Handbook of Tropical Foods. Marcel Dekker New York pp 469-488.

[4] Charley VL (1999). The Prevention of microbiological spoilage in fresh fruit In: Journal of Science and Food Agriculture. 10: 399 400.

[5] Duckwort RF (1966). Fruits and Vegetables. Per grammon Great Britain pp 162-165.

[6] Franzier WC,Westhoff DC (1991). Food Microbiology (3rd ed.) Tata Mc GrawHill publishing Company Ltd. New Delhi pp 17-21.

[7] Holtmeyer MG, Wallin JR (1981). Incidence and Distribution of airborne spores of Aspergillus flavus, In: Plant Disease 6: 54-60.

[8] Ihekeronye AI, Ngoddy PO (1985). Integrated Food Science and Technology for the tropics, Macmillan Publishers Ltd. London pp 385 .

[9] Lloyd BB (1993). Fungi in food. An Overview In: Encyclopeadia of Food Science, Food Technology and Nutrition. Academic Press Ltd. London pp. 4327-4337.

[10] Menzel C (1994). Tropical and subtropical Fruits. Encyclopeadia of Agricultural Science 4: 375-378. Robert AS, Ellen SN (1998).

[11] Introduction to Food-borne fungi. Central Bureau, voor schimmel cultures (3rd ed.) pp 56-248.

[12] Salunkhe DK (1974). Development in Technology of storage and handling of fresh fruits and vegetables. Critical Review of Food Technology 3: 15-54.

[13] Umoh IB (1998). Commonly Used Fruits in Nigeria In: Nutritional Quality of Plant Foods pp 84-89. Wenkam NS, Miller CD (1994).

[14] Papaya In: Encyclopeadia of Food Science and Technology. Academic press Ltd. London 2: $3408-3411$. William CN, Chew YW, Rajartham JH (1980).

[15] Trees and Field Crops of the Wetter regions of the tropics.Longman Group Ltd. London pp 262. 